\title{
Benefit sharing in health research
}

\author{
S Mahomed, ${ }^{1}$ BCom, LLB, LLM, PhD candidate; I Sanne, ${ }^{2}$ MB BCh, FCP, DTM\&H \\ ${ }^{1}$ Steve Biko Centre for Bioethics, Faculty of Health Sciences, University of the Witwatersrand, Johannesburg, South Africa \\ ${ }^{2}$ Managing director; Right to Care, Department of Medicine, Clinical HIV Research Unit, Internal Medicine and Infectious Diseases, University of the \\ Witwatersrand, Johannesburg, South Africa
}

Corresponding author: S Mahomed (safia.mahomed@telkomsa.net)

\begin{abstract}
The necessity of benefit sharing may be questioned when research activities are funded by international sources within a developing country. Benefit sharing is a topic which remains uncertain in the context of genetic research, particularly with regard to how and with whom benefits should be shared. A Material Transfer Agreement (MTA) is one way (and in some instances the only way) in which the transfer of human biological materials is regulated. With biobank research increasing and the historical exploitation of research participants in Africa a reality, it is essential that the transfer of human tissues across national boundaries is regulated with specific regard to the sharing of benefits and the respect and protection of traditional values. This paper will debate the requirement of benefit sharing when research is undertaken; discuss its meaning in the context of genetic research; and outline some South African and international perspectives on the sharing of benefits. While this paper emphasises benefit sharing in the context of genetic research, the principles apply to all human participant research.
\end{abstract}

SAfr J BL 2015;8(2 Suppl 1):60-64. DOI:10.7196/SAJBL.8012

Benefit sharing is the process or act of sharing in the benefits that derive from research in a manner that is fair and equitable. ${ }^{[1]}$ When considering benefits generated from genetic research, it is unclear how, with whom and by which mechanisms these benefits should be shared, as this area of discussion is somewhat unexplored. ${ }^{[2]}$ In addition, the necessity for benefit sharing may be resisted specifically when international institutions from the developed world fund research projects within a developing world country. However, the idea of benefit sharing must be balanced with public interests and population health. ${ }^{[2,3]}$ The philosophical principle behind the concept of benefit sharing is simple and may be argued as a matter of justice. ${ }^{[4]}$ Those who contribute to scientific research ought to share in its benefits. ${ }^{[4]}$ This is particularly relevant in terms of health research, when the exploitation of South Africa (SA) and the developing world by developed world countries is considered. ${ }^{[2,5]}$ This inequity still exists in certain spheres and needs to be corrected in order to restore equilibrium. ${ }^{[2]} \mathrm{A}$ benefit should be received by research participants and/or the institution which provides the samples for the utilisation of their genetic resources and/or resources. ${ }^{[2]}$ With the use of two case studies and relevant national and international laws and guidelines, this paper will debate the requirement of benefit sharing when research is undertaken; discuss its meaning in the context of genetic research; and outline some SA and international perspectives on the sharing of benefits. While this paper emphasises benefit sharing in the context of genetic research, the principles apply to all human participant research.

\section{The importance of benefit sharing when research is undertaken and its meaning in the context of genetic research}

Reliance on the use of human biobanks for research purposes has increased. In addition, the capacity, size and number of biobanks, has intensified. ${ }^{[2]}$ Human biobanks are capable of storing a vast array of genetic data including stem cells for indefinite periods, for uses that may not be established at the time the initial protocol is approved (secondary uses). Ethico-legal complications that storage of data for indefinite periods gives rise to, include (but are not limited to): confidentiality; privacy; ownership; intellectual property; informed consent for secondary uses; and benefit sharing. ${ }^{[2]}$ Justifiably, the complexities that result with the advances challenge local and international ethico-legal frameworks. Of considerable importance and debate is the notion of benefit sharing.

There is argument that participation in scientific research should always be altruistic in nature. This is how access to human genetic resources has been governed historically in prosperous nations. ${ }^{[6]}$ However, exporting this notion into developing countries could lead to the emergence of serious concerns around exploitation. A discussion of two relevant cases below, that involve benefit sharing mechanisms, describe how positive outcomes could be arrived at while engaging in benefit sharing within developing world communities.

\section{The Majengo case study}

The Majengo sex workers case involved follow-up studies on 850 female sex workers in Kenya. It was thought that they could contribute to the development of a vaccine against HIV. This was part of an ongoing collaborative project by researchers from the universities of Nairobi and Manitoba. ${ }^{[6,7]}$ The women were extremely socio-economically disadvantaged and unable to access quality healthcare in any other way than through their involvement in the clinic which was set up by the research team. ${ }^{[8]}$ The women provided individual informed consent to participate in the ongoing study which utilised their blood, cervical, vaginal and saliva samples. ${ }^{[7,8]}$ The Kenyan regulatory environment includes access to non-human genetic resources and subsequent benefit sharing thereof. However, no regulation or policy existed in respect of human genetic resources. 
In 2005, national guidelines for research and development of HIV/ AIDS vaccines ${ }^{[7,9]}$ were developed in specific response to the Majengo case. These guidelines provide a framework for addressing issues of financial compensation for research participants through Material Transfer Agreements (MTAs) and Research and Development Agreements. ${ }^{[7,9]}$ The guideline's MTA template provides for the 'fair and equitable sharing of benefits' derived from the use of biological materials. ${ }^{[10]}$ An argument has been made that benefit sharing agreements could effectively be incorporated into the cooperative research and development agreements. These agreements will then be binding and enforceable in domestic law. ${ }^{[7,8]}$ The Kenyan guidelines further require science and ethics committees in the country to verify the ethical integrity of HIV/AIDS vaccine trial protocols in accordance with internationally accepted ethical guidelines, for example, the ethical considerations in HIV preventative vaccine research of the joint United Nations programme on HIV/AIDS (UNAIDS). ${ }^{[7,9]}$ Guidance Point 10 of the aforementioned document states that: 'The research protocol should outline the benefits that persons participating in HIV preventative vaccine trials should experience as a result of their participation. Care should be taken so that these are not presented in a way that unduly influences freedom of choice in participation. ${ }^{[11]}$ While this guidance document is not legally enforceable, it does list what should be considered as minimum benefits for participants in HIV preventative vaccine trials.

The main benefit received by the Majengo participants in the study was healthcare. ${ }^{[7]}$ Prior to the research team establishing a clinic in the slums of Majengo, the participants had no option but to utilise a treatment centre in Nairobi, where services were poor and where healthcare providers discriminated against sex workers. ${ }^{[7,8,12]}$ The sex workers now have non-discriminatory access to healthcare within walking distance. Apart from the direct benefits in terms of healthcare, the clinic also offers a 'safe haven' ${ }^{17,8]}$ which enables the women to form new relationships, social networks and develop a sense of solidarity, creating a community environment. Additionally, research publications have brought the participants international exposure which could assist in safeguarding the women's rights to any benefits that may accrue from ongoing research activities. This case outlines a situation where, as a direct result of the research process, participants benefited both physically and socially by gaining access to much needed healthcare. The research also displayed that, with the right motivation, a disadvantaged and poor population could manage the demands of antiretroviral treatment and achieve the same adherence levels as the general population. This unforeseen outcome is of great significance and benefit to all those affected by HIV/AIDS, independent from the search for a successful preventative vaccine. ${ }^{[7,8]}$

\section{The San Hoodia case}

The next scenario does not involve human genetic material; however, it is an example of how one of the first benefit sharing agreements was negotiated in SA in the absence of an enabling domestic legal environment. The San people (among the oldest communities in southern Africa) historically acquired traditional knowledge on the use of Hoodia gordonii, a moist plant found in the Kalahari desert, which the San have customarily consumed to limit hunger on their lengthy, tiring journeys. ${ }^{[13]}$ The San people were at first unaware that the South African Council for Scientific and Industrial Research (CSIR), an arm of the SA government, were patenting an appetite suppressant which was produced from the Hoodia plant. ${ }^{[13]}$ No credible clinical trials have, to date, documented its safety or efficacy. The CSIR also had plans to commercialise a Hoodia pharmaceutical product without the San people providing their consent, and there was no discussion surrounding the sharing of benefits derived from the subsequent commercialisation. ${ }^{[13]}$ The CSIR and Phytopharm, a pharmaceutical company with a plant extract division, negotiated an exclusive license that transferred rights for research and commercial use of the patent for the development of Hoodia products. Phytopharm then granted licenses to Pfizer and the food multinational, Unilever. ${ }^{[13]}$ With the involvement of NGOs, in 2003 the San people and the CSIR negotiated one of the first benefit sharing agreements. ${ }^{[13]}$ This provided the San with a share of the royalties derived from the sale of the products containing Hoodia. ${ }^{[13]}$ The benefit sharing agreement received criticism; ${ }^{[13]}$ however, although far from perfect, it is an example for potential future benefit sharing agreements which allow for communities to receive recognition for their traditional knowledge and share in the commercialisation of products based on their knowledge. ${ }^{[13]}$

\section{South African law and guidelines with regard to the sharing of benefits The Biodiversity Act 10 of 2004}

In SA, the Biodiversity Act 10 of $2004^{[14]}$ is the only legal document that sets out what a 'benefit' may constitute for bioprospecting or any other kind of research involving indigenous biological resources. The Act specifically excludes human material from its application, but it does provide for (among others): the sustainable use of indigenous biological resources; and the fair and equitable sharing of benefits arising from bioprospecting or involving indigenous biological resources. ${ }^{[14]}$ Currently, section 1 of the Act defines a benefit to include: 'both monetary and non-monetary returns..[14] Therefore, local capacity building would form a benefit as provided for under the Act. Section 81(1)(b) of the Act also: 'obligates applicants to apply for a permit before any export of the resource is undertaken for research purposes.'[14] In addition, section 82(1)(b) of the Act: 'protects the interests of any organ of state or community providing or giving access to the indigenous biological resources.' The involvement of the indigenous community is measured before any permit referred to above is issued. ${ }^{[14]}$ With regard to the protection of an indigenous community, the issuing authority will consider the traditional uses of the indigenous biological resources or the knowledge of, or discoveries about the indigenous biological resources before authorising a permit for use of the resources. ${ }^{[14]}$ Section $82(2)(b)$ of the Act makes it mandatory for the applicant and stakeholder (i.e. a person, organ of state, community or indigenous community) to enter into an MTA which regulates the provision of or access to the resources and a benefit sharing agreement that provides for sharing by the stakeholder in any future benefits that may be derived from the relevant bioprospecting. ${ }^{[15]}$ It is important to note that a permit will not be granted if the preceding two agreements are not entered into by the parties. Section 83 of the Act sets out that the benefit sharing agreement must specify: 'the type of indigenous biological resources to which the relevant bioprospecting relates; the area or source from which the indigenous biological resources are to be collected or obtained; the quantity of resources to be collected or obtained; any traditional uses of the resources by an indigenous community; and 
the present potential uses of the resources.'[16] The benefit sharing agreement must also name the parties to the agreement; set out the manner and extent to which the resources are to be utilised; set out the manner and extent to which the stakeholder will share in any benefits that may arise; provide for regular review of the agreement; and comply with any other matters that may be prescribed. ${ }^{[17]}$ Section 83(5) of the Act stipulates that the agreement or any amendment thereto will have to be submitted to the Minister for approval and will not take effect unless approved by the Minister. Section 85 of the Act provides for any monies arising from the benefit sharing agreement and MTA and directs that such monies are kept in a bioprospecting trust fund and considered to be trust money managed by the director general who will be accountable for these funds.

As stated above, the Biodiversity Act is the only SA piece of legislation that regulates benefit sharing agreements in terms of providing a definition and outlining what the agreement should contain. Although human material is excluded from the Act, it is a relevant starting point to develop a benefit sharing mechanism of a similar nature, relevant to research involving human material, as has been done recently in the University of the Witwatersrand's MTA template.

\section{University of the Witwatersrand's Material Transfer Agreement template}

During 2014, the University of the Witwatersrand approved an MTA template ${ }^{[1]}$ for human biological materials to be used by its researchers. The definitions section of the template defines benefit sharing as: 'a process or act of sharing in the benefits that derive from the research in a manner that is fair and equitable..[1] The template also defines benefits to include among others: 'the sharing of information, use of research results, royalties, acknowledgement of the provider as the source of the materials, publication rights, transfer of technology or materials, and capacity building.[1] In an attempt to foster equitable benefit sharing mechanisms, the template provides that the sharing of benefits should be discussed between the parties before any materials are transferred for research purposes.

\section{Ethics in health research: Principles, structures and processes}

This ethical guideline provides guidance in respect of all forms of research involving animals, human participants, human biological materials and data collected from living or deceased persons, including human embryos, fetuses, fetal tissue, reproductive materials and stem cells. ${ }^{[18]}$ South African research ethics committees are encouraged to adopt these principles in assessing all health research projects. ${ }^{[18]}$ The guideline provides that a risk-benefit analysis should precede carrying out the research and that the likelihood of benefits should outweigh the anticipated risk of harm to participants. The guideline further indicates that there should be a fair balance of risks and benefits among all role-players involved in research, including participants, participating communities and the broader society, in order to express the principle of equality in the research context. In addition, there should be a reasonable likelihood that the population from which participants are drawn, will benefit from the research results, if not immediately, then in the future. ${ }^{[18]}$

It may be argued that ethical guidelines have no legal status. However, it is important to note that in terms of current legal literature, ethical guidelines are considered as customary international law. ${ }^{[19]}$ In order to qualify as customary international law, an ethics guideline must be supported by the consistency and generality of being widely accepted as practice. ${ }^{[19,20]}$ Nevertheless, there is still a large gap between legislative documents with legal status and ethical guidelines. ${ }^{[19,20]}$ Furthermore, it is difficult to compel objectors to the ethical guidelines to comply, which raises concerns surrounding the alleged binding nature of customary international law. ${ }^{[19]}$ Section 39(1)(b) of the Constitution of South Africa instructs that when the Bill of Rights is interpreted, a court, tribunal or forum must consider international law. ${ }^{[21]}$ However, without a legal requirement for the incorporation of benefit sharing agreements into the research process in SA, it is left up to ethics committees to regulate these arrangements on a case-by-case basis. In the absence of clear domestic legislation regarding benefit sharing in the context of human genetic research, a brief description of certain international perspectives relevant to research on human material will follow.

\section{International perspectives on benefit sharing The Nagoya protocol on access to genetic resources and the fair and equitable sharing of benefits arising from their utilisation}

The Nagoya protocol on access to genetic resources and the fair and equitable sharing of benefits arising from their utilisation $(A B S)^{[22]}$ is a supplementary agreement to the Convention on Biological Diversity (CBD). ${ }^{[23]}$ South Africa is a signatory to the protocol which provides for the effective implementation of the fair and equitable sharing of benefits arising out of the utilisation of genetic resources. ${ }^{[23]}$ The Protocol was adopted on 29 October 2010 in Nagoya, Japan. Of particular relevance is the reference to human genetic resources in the introduction. Similarly, it is important that: 'access to affordable treatments by those in need especially in developing countries' is included in Article 8 of the Protocol, among the special considerations that must be observed when regulating access to genetic resources. ${ }^{[22,23]}$

The Protocol creates incentives to safeguard and sustainably use genetic resources, therefore enhancing the contribution of biodiversity to development and human well-being. ${ }^{[22,23]}$ Among the parties who are required to provide their informed consent and agree to mutual terms are indigenous and local communities that hold genetic resources and/or associated traditional knowledge. ${ }^{[23]}$ With regard to benefit sharing, each party is obligated to take administrative, legislative or policy measures to ensure that benefits are shared fairly and equitably with the party who provides the resources. ${ }^{[2]}$ Capacity building is also emphasised in the Protocol. Parties must participate in capacity development, capacity building, and strengthening of human resources and institutional capacities. ${ }^{[24]}$

Under the Protocol, communities who hold genetic resources and related traditional knowledge are afforded extensive consideration and protection:

- Prior informed consent must be provided by these communities for utilisation and access to their resources.

- Benefits must be shared in a fair and equal manner with the communities whose genetic resources or traditional knowledge were utilised. 
- Parties shall establish mechanisms to notify users of traditional knowledge about their obligations.

- Parties shall organise community meetings, establish a help desk for communities, and involve communities in the implementation of the Protocol, to increase awareness of genetic resources and traditional knowledge held by communities.

- The Protocol further calls for capacities of communities to be improved, which will enable their effective participation in implementing the objectives of the Protocol. ${ }^{[22-24]}$

\section{The Declaration on the Human Genome and Human Rights}

The Declaration on the Human Genome and Human Rights ${ }^{[25]}$ was adopted unanimously and by acclamation at UNESCO's 29th general conference on 11 November 1997. The following year, the United Nations General Assembly endorsed the Declaration. Article 12(a) of the 1997 Declaration embraces the theory of sharing benefits on the basis of common property and distributive justice. It states that: 'Benefits from advances in biology, genetics and medicine concerning the human genome, shall be made available to all, with due regard for the dignity and human rights of each individual'. This implies that benefits concerning the human genome may be considered common property and therefore be made available to all. ${ }^{[19,25]}$ Article 19(a) iii indicates that: 'when international co-operation occurs, developing countries should benefit from the achievements of scientific and technological research in order for their use in favour of economic and social progress to be for the benefit of all'. Two other international guideline documents, while not specific to genetic research, are also worthy of a brief discussion in this section and follow below.

\section{The Council for International Organisations and Medical Sciences international ethical guidelines for biomedical research involving human subjects}

The goals of the Council for International Organisations and Medical Sciences (CIOMS) international ethical guidelines for biomedical research involving human subjects ${ }^{[26]}$ are to facilitate and promote international activities in the field of biomedical sciences, in collaboration with the United Nations and the World Health Organization (WHO). ${ }^{[26,27]}$ The CIOMS guidelines (developed in conjunction with the WHO) were published in 1993, and updated in 2002. The guidelines provide broad support, with regard to benefit sharing, and stipulate that a research project should leave low resource countries or communities better off than previously or, at least, not worse off. ${ }^{[26]}$ The guidelines further stipulate that the project should be responsive to health needs and priorities in that any product developed is made reasonably available, and as far as possible leave the population in a better position to obtain effective healthcare and protect its own health. ${ }^{[26]}$

The CIOMS guidelines that deal directly with benefit sharing are: guideline 10, which focuses on post-study access to beneficial interventions and responsiveness to health needs; and guideline 21 which deals with the provision of services that are necessary for making a beneficial intervention and/or product available. ${ }^{[26]}$

Guideline 10 relates to research in populations and communities with limited resources. Before undertaking research in a population or community with limited resources, the sponsor and the investigator must make every effort to ensure that the research is responsive to the health needs and the priorities of the population or community in which it is to be carried out. ${ }^{[26]}$ Furthermore, every effort must be made to ensure that any intervention or product developed, or knowledge generated, will be made reasonably available for the benefit of that population or community. ${ }^{[26]}$ However, the issue of 'reasonable availability' is complex and determined on a case-bycase basis. ${ }^{[26]}$ The guidelines provide that in general, if there is good reason to believe that a product developed or knowledge generated by research is unlikely to be reasonably available to, or applied to the benefit of, the population of a proposed host country or community after the conclusion of the research, it is unethical to conduct the research in that country or community. ${ }^{[26]}$

\section{The Declaration of Helsinki}

The Declaration of Helsinki ${ }^{[28]}$ was first adopted at the 1964 World Medical Association General Assembly in Helsinki. Its purpose is to provide ethical principles for medical research involving human subjects, including research on identifiable human material and data. ${ }^{[28]}$ Section 19 of the Declaration explains that certain groups or individuals may be considered to be vulnerable and should receive considered protection. ${ }^{[28]}$ Section 20 states that medical research with a vulnerable group is only justified if the research is responsive to the health needs or priorities of the group. ${ }^{[28]}$ Additionally, the group should stand to benefit from the knowledge, practices or interventions that result from the research. ${ }^{[28]}$

\section{Discussion and conclusion}

From the above analysis, it is clear that the international guidelines echo a similar message with regard to benefit sharing. In addition, it is apparent that benefit sharing in respect of human material does not imply a monetary transaction only. Any form of advantage, assistance or upliftment to the participant, community and/or providing institution could constitute a benefit and enhance the trust relationship between research participants and institutions, which in turn will foster progress in terms of genetic research. The international guidelines emphasise the importance of the concept of benefit sharing specifically with regard to developing world countries. With recent developments in the biotechnology arena, it is not implausible that numerous tissue samples may be leaving SA and Africa for genetic research purposes. ${ }^{[29]}$ The Majengo and San cases outline the positive outcomes of benefit sharing arrangements with research participants. The University of the Witwatersrand's MTA template highlights that benefit sharing should be discussed between parties before tissues are transferred in order to foster equitable benefit sharing arrangements. Furthermore, international ethical guidelines relevant to human materials shape the importance of benefit sharing as a progressive mechanism for parties to adopt as part of the research process. According to Slabbert: ${ }^{[30]}$ 'The challenge for South Africa is to find a benefit-sharing model that tempers (not diminish) commercial interests; that redresses economic imbalance; and that gives research participants a more fair and active role in influencing the sharing of benefits... ${ }^{[30]}$ The Biodiversity Act provides an excellent starting point to develop a model similar in nature for human biological material. This will enhance confidence and trust in genetic research, which will in turn ensure a sustainable research environment for both research participants and institutions. 


\section{References}

1. University of the Witwatersrand Human Research Ethics Committee Medical. Material Transfer Agreement for Human Biological Materials. Compiled by the Biobanks Ethics Committee. Johannesburg, University of the Witwatersrand, 2014. http://www.wits.ac.za/academic/researchsupport/19112/ethics_application_ forms_guidance_notes_and_policy_documents.html (accessed 23 February 2015).

2. Mahomed S, Behrens K, Slabbert MN, Sanne I. Managing human tissue transfer across national boundaries: An approach from a South African institution. Developing World Bioethics. 2015 [http://onlinelibrary.wiley.com/doi/10.1111/ dewb.12080/full]

3. Cambon-Thomsen A, Rial-Sebbag E, Knoppers BM. Trends in ethical and legal frameworks for the use of human biobanks. Eur Respir J 2007;30(2):373-382. [http://dx.doi.org/10.1183/09031936.00165006]

4. Arnason G, Schroeder D. Exploring Central Philosophical Concepts in Benefit Sharing: Vulnerability, Exploitation and Undue Inducement. In: Schroeder D, Lucas JC. Benefit Sharing: From Biodiversity to Human Genetics. New York: Springer.2013;9-31.

5. Chennells RS. Equitable access to human biological resources in developing countries: Benefit sharing without undue inducement (in press). United Kingdom: School of Health: University of Central Lancashire, PhD thesis, 2014.

6. Lucas JC, Schroeder D, Arnason G, et al. Donating Human Samples: Who Benefits? Cases from Iceland, Kenya and Indonesia. In: Schroeder D, Lucas JC. Benefit Sharing: From Biodiversity to Human Genetics. New York: Springer 2013;95-128.

7. Lucas JC, Schroeder D, Chennells R, et al. Sharing Traditional Knowledge: Who benefits? Cases from India, Nigeria, Mexico and South Africa. In: Schroeder D, Lucas JC. Benefit Sharing: From Biodiversity to Human Genetics. New York: Springer 2013;65-93.

8. Andanda P, Cook Lucas J. Majengo HIV/AIDS Research Case. A Report for GenBenefit, 2007. https://www.uclan.ac.uk/research/explore/projects/assets/ cpe_genbenefit_nairobi_case.pdf (accessed 24 February 2015).

9. Kenyan Ministry of Health. Kenyan Ministry of Health National Guidelines 2005. https://www.globalgiving.org/pfil/1108/projdoc.pdf (accessed 21 February 2015).

10. Ministry of Health. National Kenyan Guidelines for Research and Development of HIV/AIDS Vaccines. Appendix 5: Biological Material Transfer Agreement. Kenya: Ministry of Health 2005. https://www.globalgiving.org/pfil/1108/projdoc.pdf (accessed 21 February 2015).

11. United Nations. Ethical Considerations in HIV preventative vaccine research. UNAIDS guidance document. Joint United Nations Programme on HIV/AIDS. Geneva: United Nations 2000. http://data.unaids.org/publications/IRC-pub01/ JC072-EthicalCons_en.pdf (accessed 22 February 2015).

12. Bandewar SVS, Kimani J, Lavery JV. The origins of a research community in the Majengo observational cohort study, Nairobi, Kenya. BMC Public Health 2010;10:630. [http://dx.doi.org/10.1186/1471-2458-10-630]

13. Tellez VM. Recognising the traditional knowledge of the San people: The Hoodia case of benefit sharing. http://www.ipngos.org/NGO\%20Briefings/Hoodia\%20 case\%20of\%20benefit\%20sharing.pdf (accessed 22 February 2015).

14. Republic of South Africa. Biodiversity Act 10. Government Gazette 2004
15. Republic of South Africa. Biodiversity Act 10, Section 82(2)(b)(i)\&(ii). Government Gazette 2004.

16. Republic of South Africa. Biodiversity Act 10, Section 83(1)(b). Government Gazette 2004

17. Republic of South Africa. Biodiversity Act 10, Section 83(1)(c) - (g). Government Gazette 2004

18. Republic of South Africa. Department of Health Ethics in health research: Principles, Structures and Processes. 2nd ed. Pretoria: Department of Health, 2015.

19. Andanda P, Schroeder D, Chaturvedi S, et al. Legal Frameworks for Benefit Sharing: From Biodiversity to Human Genomics. In: Schroeder D, Lucas JC. Benefit Sharing: From Biodiversity to Human Genetics. New York: Springer 2013;333- 364.

20. Brownlie I. Principles of Public International Law. New York: Oxford University Press, 2003.

21. Republic of South Africa. Constitution of the Republic of South Africa Act 108 Government Gazette 1996

22. Nagoya Protocol on Access to Genetic Resources and the Fair and Equitable Sharing of Benefits Arising from their Utilisation. Secretariat of the Convention on Biological Diversity, 2011 https://www.cbd.int/abs/doc/protocol/nagoyaprotocol-en.pdf (accessed 12 February 2015).

23. The Convention on Biological Diversity 1992 http://www.cbd.int/abs/about/ (accessed 13 February 2015).

24. Kamau EC, Fedder B, Winter G. The Nagoya Protocol on access to genetic resources and benefit sharing: What is new and what are the implications for provider and user countries and the scientific community? Law, Environment and Development Journal 2010; 6(3):246-262.

25. United Nations Educational, Scientific and Cultural Organisation. Universal Declaration on the Human Genome and Human Rights. Geneva: United Nations, 1997. http://www.unesco.org/new/en/social-and-human-sciences/themes/ bioethics/human-genome-and-human-rights/ (accessed 15 February 2015)

26. The Council for International Organisations of Medical Sciences (CIOMS) in collaboration with the World Health Organization (WHO). International Ethical Guidelines for Biomedical Research involving Human Subjects. Geneva: World Health Organization, 2002. http://www.cioms.ch/publications/layout guide2002.pdf (accessed 14 February 2015).

27. Macrae DJ. The Council for International Organisations and Medical Sciences (CIOMS) guidelines on ethics of clinical trials. Proc Am Thorac Soc 2007:4(2):176-179.

28. World Medical Association. WMA Declaration of Helsinki - Ethical Principles for Medical Research involving Human Subjects. Helsinki:World Medical Association, 1964. http://www.wma.net/en/30publications/10policies/b3/ (accessed 20 March 2015).

29. Sathar A, Dhai A, Van der Linde S. Collaborative international research: Ethical and regulatory issues pertaining to human biological materials at a South African institutional research ethics committee. Dev World Bioeth 2014;14(3):150-157. [http://dx.doi.org/10.1111/dewb.12018]

30. Slabbert MN. The legal regulation of access and benefit-sharing of human genetic resources in South Africa. J Contemp Roman-Dutch Law 2011;74:605. 